\title{
Gender Differences Concerning Physical Activity Beliefs and Practices among Fourth and Fifth Graders in Rural Virginia
}

\author{
Tenesha M. McDuffie ${ }^{a}$, Mikaela A. Brooks ${ }^{\text {b}}$, Emily DeVilliers ${ }^{a}$, Ashley N. Kelleran ${ }^{\text {, }}$, Anna K. Leal d, \\ a Bridgewater College, Department of Health \& Human Sciences, Bridgewater, VA 22812, U.S.A. \\ b Eastern Mennonite University, Department of Athletics, Harrisonburg, VA 22802, U.S.A. \\ ${ }^{c}$ Rockingham County Public Schools, Elementary Teachers, Harrisonburg, VA 22802, U.S.A. \\ d Centenary College of Louisiana, Biology Department, Shreveport, LA 71104, U.S.A. \\ *Corresponding author Email: aleal@centenary.edu \\ DOI: https://doi.org/10.34256/ijpefs2147
}

Received: 21-08-2021, Revised: 16-11-2021; Accepted: 16-11-2021; Published: 19-11-2021

\begin{abstract}
Cardiovascular disease is the leading cause of death in the United States. Physical activity (PA) is a known preventative factor. It is recommended that children participate in 60 minutes of PA daily, but most do not meet these guidelines. Further, boys, aged 8-17 years, spend more time in PA than girls of the same age. The purposes of this study were to identify gender differences in PA beliefs and practices among fourth and fifth graders and to determine when gender disparities in self-confidence regarding PA and fitness occur. Subjects were 41 fourth (19 boys; 22 girls) and 33 fifth (16 boys; 17 girls) graders in a public elementary school in the rural northwest. They participated in the FitnessGram, a nationwide assessment of flexibility, aerobic capacity, and muscular strength and endurance, and a proctored survey about their PA beliefs, self-confidence, and participation. There were no differences in FitnessGram data between boys and girls for aerobic capacity or muscular strength and endurance, but girls had increased flexibility when compared to boys in both grades. Importantly, survey results showed fifth grade girls had less confidence they could improve their physical fitness $(p=0.002)$ or their overall health ( $p=0.004$ ) when compared to fourth grade girls. Research is needed to determine how these changes in self-confidence contribute to the gender gap in time spent in PA. We recommend physical education programs throughout all grades teach healthy behaviors, including time spent in PA, and work to build and maintain self-confidence in girls.
\end{abstract}

Keywords: Physical activity, Gender gap, Children, Self-confidence

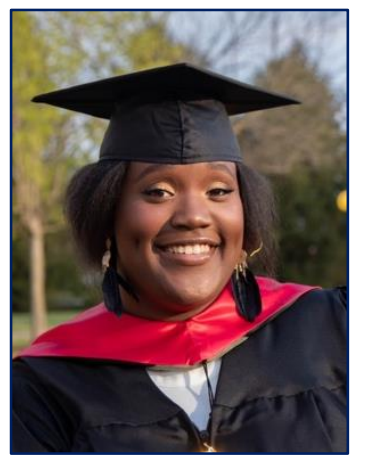

Tenesha McDuffie, B.S. (she/her) is currently an instructional assistant for Extended Content Standards (ECS) for Wake County Public School Systems and works with students across the autistic spectrum. She graduated with her B.S in Health and Exercise Science from Bridgewater College. During her time at Bridgewater College, she conducted a longitudinal study analyzing fourth and fifth grader's beliefs about physical activity. This research produced two abstract publications at the Southeastern American College of Sports Medicine (SEACSM) Conference and McDuffie received the Leadership and Diversity Training (LDPT) scholarship for this work. She also was a student manager for two years at the campus fitness center, where she helped with training and leadership. McDuffie is now working towards a certification in Certified Health Education Specialist (CHES) and continues to pursue her passion of community health and wellness serving minority communities while making a prolonged impact in her community.

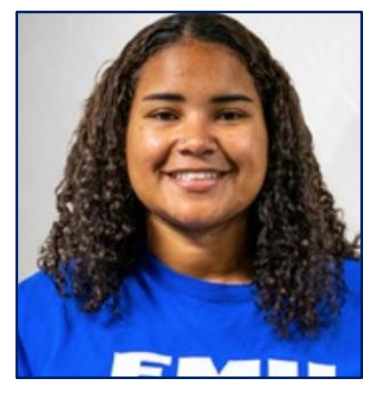

Mikaela A. Brooks, B.S. is an assistant coach for Women's Lacrosse at Eastern Mennonite University in Harrisonburg, Virginia. Brooks earned her bachelor's degree in Health and Exercise Science from Bridgewater College in Bridgewater, Virginia. She was a strength and conditioning student 
assistant for 2 years at Bridgewater College. She is also a member of IWLCA Leaders of Diversity.

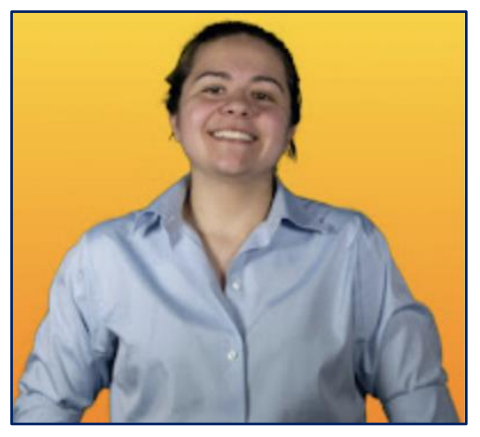

Emily DeVilliers, B.S. graduated from Bridgewater College with a B.S. in Health and Physical Education. During her college career, she managed the Women's Basketball Team and student taught elementary school P.E. She also researched elementary school students' physical activity beliefs and practices and this research resulted in an abstract publication and poster presentation at the Southeastern American College of Sports Medicine (SEACSM) Conference. DeVilliers is currently a Night Floor manager at Costco Wholesale in Connecticut. She continues to use the skills and competencies she learned at Bridgewater College in her role as manager of a 20-person team. Professionally, DeVilliers plans to continue her upward path within management at Costco Wholesale. Eventually, she wants to add women's and men's high school basketball and track and field coaching to her list of accomplishments.

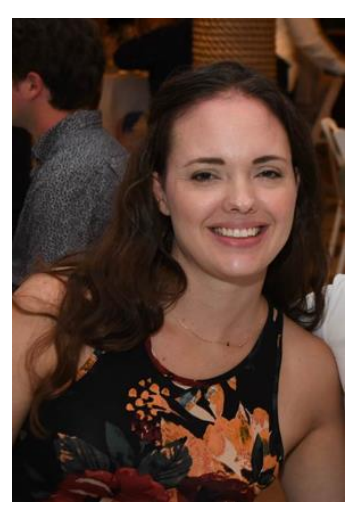

Ashley Kelleran, M.S. is a special education teacher with 8 years of public-school teaching experience. She earned her B.S. in Early Childhood, Elementary, and Special Education from Juniata College in Huntingdon, Pennsylvania followed by an M.S. in Emotional Disturbances and Autism from the University of North Dakota in Grand

Forks, North Dakota. Kelleran has co-taught middle school science and math to 7th and 8th grade students and has also taught in a collaborative setting serving 4th grade students. Kelleran's last placement was as the lead teacher in a self-contained K-5 autism classroom.

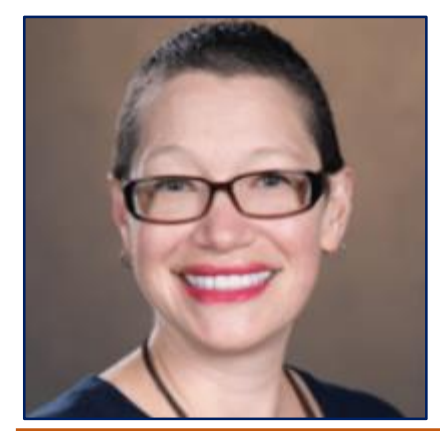

Anna K. Leal, Ph.D. is an assistant professor of biology at Centenary College of Louisiana in Shreveport. Leal earned a $\mathrm{PhD}$ in biomedical engineering from the University of Texas
Southwestern Medical Center in Dallas and completed a postdoctoral fellowship at the Heart \& Vascular Institute at the Pennsylvania State University College of Medicine. She has taught undergraduate courses including anatomy and physiology and exercise physiology. Leal's research focuses on gender differences concerning physical activity in elementary school students. One of her goals is to increase and promote diversity in biology education. She is a member of the American Physiological Society Diversity, Equity \& Inclusion Committee and co-chairs the Centenary College Diversity Committee.

\section{Introduction}

In the United States, cardiovascular disease is the leading cause of death for people of all ages and most racial and ethnic groups and in 2018, more than 868,000 people died from cardiac-related events. Direct and indirect costs of cardiovascular disease, which include health care service, medicine, and lost productivity, totaled $\$ 363.4$ billion in 2016-17 [1]. Risk factors for cardiovascular disease include: smoking, high blood pressure, high cholesterol, being overweight or obese, diabetes, eating an unhealthy diet, excessive alcohol use, and physical inactivity [1]. On the other hand, physical activity (PA) and physical fitness have been identified as preventative factors for cardiovascular disease and other chronic ailments [2]. These risk factors and preventative factors may start in childhood and carry over into adulthood [3, 4]. Therefore, it is imperative that children are taught healthy habits early and that they meet daily and weekly PA recommendations. The current PA recommendations, which were updated in 2007 by the American College of Sports Medicine and the American Heart Association, state that healthy adults participate in a minimum of 30 minutes of moderate-intensity aerobic exercise on 5 days each week or a minimum of 20 minutes of high-intensity aerobic exercise on 3 days per week in addition to muscle-strengthening activities on two or more days per week [5]. Based on a nationally representative sample in 2018 , only $24.0 \%$ of healthy adults met these guidelines [6]. The recommendation for children and adolescents ages 6 through 17 years is that they participate in 60 minutes or more of moderate-to-vigorous PA daily, which should include aerobic, muscle-strengthening, and bone-strengthening movements [7]. As with adults, most children and adolescents are not meeting these recommendations. 
According to the 2019 High School Youth Risk Behavior Survey (YRBS), $64.7 \%$ of girls and $47.2 \%$ of boys were not physically active at least 60 minutes per day on 5 or more days per week and $84.6 \%$ of girls and $69.1 \%$ of boys were not physically active at least 60 minutes per day on all 7 days [8]. Further, for both time periods, girls were significantly more likely than boys to not be physically active. Other questions on the YRBS pertain to physical education (PE) class attendance. 2019 survey results showed $51.4 \%$ of girls and $44.6 \%$ of boys did not attend PE class on one or more occasions per school week, while $77.2 \%$ of girls and $71.1 \%$ of boys did not attend a single PE class during an average school week. Again, girls were significantly more likely than boys to not attend PE class on both one or more days per week and on all 5 days of an average school week [8]. Data from the 2019 Middle School YRBS showed similar results [9]. In the state where our study was conducted, $54.7 \%$ of girls and $43.1 \%$ of boys were not physically active for at least 60 minutes per day on 5 or more days per week. Further, $77.7 \%$ of girls and $64.4 \%$ of boys were not physically active at least 60 minutes per day on all 7 days. Gender differences over both 5 or more days and 7 days were statistically significant [9]. Data from our state about PE class attendance was not available. The 2019 YRBS data corroborates that as students advance through school, their participation in daily PA decreases and significant gender disparities in PA are evident in both middle and high school [10-14].

In fact, gender disparities in PA begin in elementary school and sometimes, even earlier [10, $14,15]$. Boys, 8-17 years, spend more time in PA than girls of the same age $[11,16]$. Data shows that girls' participation in organized sport is less than that of boys' participation [17]. Additionally, studies have shown that girls are less active during unstructured recess, free play before school, and free play at lunchtime $[18,19]$. While studies comparing activity levels of middle school boys and girls during organized school PE have been conflicting, results of one study showed boys were more active in PE than girls [18, 20]. Social, cultural, and biological factors contribute to this gender gap [21]. One study in adolescents aged 12-16 years found that boys received more peer support to engage in after-school and weekend PA than girls [22]. This is important because parental and peer encouragement to participate in PA has been linked to an increase in PA outside of school [23]. It has also been shown that children aged 3-18 years with more active parents are more active themselves [24-26]. Finally, the biological effects of puberty may also contribute to the gender gap in PA $[16,29,30]$. The increase in girls' fat mass and boys' muscle mass can affect balance and coordination, motor skills, and cardiorespiratory fitness, all of which could affect an individual's sport and PA confidence and preference [16, 27-29].

Psychological factors also affect PA behavior. According to social cognitive theory, self-efficacy (confidence in one's capabilities) is an important determinant of motivation and action: in this case the action is PA and exercise [30]. A study conducted in middle school students showed that self-esteem, perceived benefits of exercise, perceived athletic ability, and belief in one's ability to maintain commitments all positively correlated with current exercise behavior and exercise intent [31]. More importantly, of these factors, perceived benefits of exercise and self-esteem showed the strongest correlation. We previously showed that women in college had less self-confidence than men in their abilities to increase PA and improve physical fitness. Women in college also perceived barriers to PA to be more discouraging and cues to action as less encouraging than men [32]. Together, these studies suggest that confidence levels and self-efficacy, in addition to social, cultural, and biological determinants, contribute to the gender gap in PA practices. Further, the contribution of confidence and self-efficacy to PA behavior and the gender disparities in PA behavior begin at an early age.

Therefore, the purpose of this study was to identify gender differences in PA beliefs and practices among elementary school fourth and fifth grade students. We also sought to determine when gender disparities in self-confidence regarding PA and fitness begin to occur. Through surveys and fitness assessments, we compiled data about elementary school students' PA patterns and attitudes as well as their perceived barriers to and cues to action for PA. These findings help elucidate how PA beliefs and perceived self-efficacy contribute to the gender gap in time spent in PA. The results of this study can be translated into PE curriculum design and into school and after-school planning so that students, especially girls, are taught and encouraged to build and maintain self-confidence in themselves and self-efficacy in their abilities to maintain PA throughout their lifespan.

\section{Materials and Methods}

This protocol was approved by the Bridgewater College Institutional Review Board. Guardian informed 
consent and personal informed assent was obtained from all subjects. Subjects were fourth and fifth grade students enrolled in a public elementary school in rural, Northwestern Virginia. Data was collected over two subsequent academic years (2017-2019). This study consisted of two parts: the FitnessGram fitness assessment and a proctored PA behaviors survey. All testing was conducted during the subjects' designated PE class time over several weeks in the Spring. Descriptions of the individual protocol components follow.

Data from the Virginia Department of Education Fitness Assessment, also known as the FitnessGram, was collected. All our measurements are listed in inches, which follows FitnessGram guidelines set by the Virginia Department of Education. This assessment is conducted annually in all Virginia elementary schools. For fourth and fifth graders, the fitness assessment measures aerobic capacity, flexibility, muscular strength, muscular endurance, and body composition. The specific tests performed were the Flexed Arm Hang, Trunk Lift, and Curl-up to assess upper body and core muscular endurance; the Progressive Aerobic Cardiovascular Endurance Run (PACER) to assess cardiorespiratory endurance; and the Back-Saver Sit-and-Reach and Shoulder Stretch to assess flexibility [33]. During the Flexed Arm Hang, students hung from a bar with their gripped hands' palms forward and their chins above the bar for as long as possible. To perform the Trunk Lift, students started by lying on a mat in a prone position (facedown). Toes were pointed and hands were placed under the thighs. The students lifted the upper body off the floor, in a slow and controlled manner, to a maximum height of 12 inches. The head was maintained in neutral alignment with the spine and the position was held long enough to allow the evaluator to measure the distance in inches from the floor to the student's chin. For the Curl-up (crunches) test, students completed as many consecutive repetitions as possible at a cadence of 20 curl-ups per minute with correct form until either the second correction or 75 curl-ups have been completed. Correct form consisted of the student lying on their back on a mat with their knees bent and feet flat on the floor. Arms were by their sides with palms facing down. To perform a curlup, students lifted their torsos and heads off the ground while sliding their arms across the floor. Their fingers needed to travel 4.5 inches across the floor before returning their heads and torsos to the mat. Form errors included: not lifting the torso, lifting the feet, not returning to the original position between repetitions, and not following the cadence. To complete the PACER test, students ran back and forth across a 20-meter distance at a specified pace that increased as the test progressed. When the student could no longer keep pace with the beeps of a standardized audio track for two subsequent times, the test ended and the number of 20-meter repetitions was recorded. This number was then used to estimate maximal oxygen consumption (VO2max). Finally, during the Back-Saver Sit-and-Reach, students removed their shoes and sat on the ground with one leg extended in front of them and their foot flat against the sit-and-reach box used to measure flexibility. The other leg was bent at the knee with the foot flat on the ground. The student then reached their fingers towards their toes as far as possible without bending the extended knee. The distance was measured in inches on the sit-and-reach box. The test was conducted twice, once with each leg bent. For the Shoulder Stretch, students touched their fingertips together behind their backs by reaching over one shoulder and under the other arm's elbow while standing. This test was completed twice, once on each side. A passing score was given if students could touch fingers on both sides [33].

In addition to participating in the FitnessGram, subjects also completed a proctored, 13-question survey. Most questions on this survey were answered on a $10 \mathrm{~cm}$ Likert scale that ranged from Low to High (Table 1). The survey determined students' beliefs about and knowledge of PA, self-confidence in their physical fitness and ability to change, and PA practices. Additionally, the survey identified cues to action for and barriers to PA changes in the elementary school student population. This questionnaire was administered during $P E$ class times and took approximately 30 minutes to complete. At the beginning of the survey, students were asked to selfreport grade level and gender. Questions 1-11 were written to determine the values and beliefs that guide the student's PA behavior and were based on the Health Belief Model (HBM). The HBM proposes that people are more inclined to engage in healthy behaviors when they think doing so can reduce a threat [34, 35]. In this survey, the healthy behavior was PA while the threat was an unhealthy heart. Students provided information about the perceived benefits of and barriers to PA (taking action) as well as the perceived likelihood of developing an unhealthy heart. Questions 1-11 also determined how cues to action and self-efficacy helped guide PA behavior. 
Table 1 - Survey questions listed with corresponding models of behavior change.

\begin{tabular}{|c|c|c|}
\hline \multicolumn{2}{|c|}{ Questions Based on Health Belief Model } & Response \\
\hline 1 & How much do you feel at risk for developing an unhealthy heart? & 0 (low) -10 (high) \\
\hline 2 & How bad do you feel the effects of an unhealthy heart are? & 0 (low) - 10 (high) \\
\hline 3 & How bad do you feel the effects of low physical activity are? & 0 (low) -10 (high) \\
\hline 4 & $\begin{array}{l}\text { How would you rate the benefits of physical activity on your } \\
\text { overall health? }\end{array}$ & 0 (low) - 10 (high) \\
\hline 5 & $\begin{array}{l}\text { How would you rate the benefits of physical activity on making } \\
\text { your heart stronger? }\end{array}$ & 0 (low) - 10 (high) \\
\hline 6 & $\begin{array}{l}\text { What prevents and/or discourages you from physical activity? } \\
\text { Taken together, how would you rate the level of their overall } \\
\text { prevention/discouragement? }\end{array}$ & $\begin{array}{l}\text { Free response, } \\
0 \text { (low) }-10 \text { (high) }\end{array}$ \\
\hline 7 & $\begin{array}{l}\text { What allows and/or encourages you to be physically active? Rate } \\
\text { their overall level of encouragement. }\end{array}$ & $\begin{array}{l}\text { Free response, } \\
0 \text { (low) }-10 \text { (high) }\end{array}$ \\
\hline 8 & $\begin{array}{l}\text { What would allow and/or encourage you to be more physically } \\
\text { active than you currently are? How would you rate the strength } \\
\text { of encouragement from these factors? }\end{array}$ & $\begin{array}{l}\text { Free response, } \\
0 \text { (low) }-10 \text { (high) }\end{array}$ \\
\hline 9 & $\begin{array}{l}\text { How much do you think you can increase your weekly physical } \\
\text { activity? }\end{array}$ & 0 (low) - 10 (high) \\
\hline 10 & How much do you think you can improve your physical fitness? & 0 (low) - 10 (high) \\
\hline 11 & How much do you think you can improve your overall health? & 0 (low) - 10 (high) \\
\hline \multicolumn{2}{|r|}{ Questions Based on Precaution Adoption Process Model } & Response \\
\hline 12 & $\begin{array}{l}\text { Have you ever heard that } 60 \mathrm{~min} / \mathrm{day} \text { of moderate or vigorous } \\
\text { physical activity makes your heart stronger? }\end{array}$ & Yes/No \\
\hline 13 & $\begin{array}{l}\text { Do you currently do } 60 \mathrm{~min} / \text { day of moderate (breathing hard to } \\
\text { where you can talk, but can't comfortably sing) or vigorous (can't } \\
\text { comfortably speak a complete sentence without stopping to } \\
\text { breathe) physical activity? }\end{array}$ & Yes/No \\
\hline
\end{tabular}

Data was analyzed using GraphPad Prism (version 9.1 .2 for Windows). Independent variables were grade level and gender. All data is reported as average \pm standard error of means (SEM). FitnessGram data was analyzed by one-way ANOVA with Tukey's multiple comparisons and chi squared tests. Survey responses on questions 1-11 were measured and reported to the nearest half centimeter on the Likert scale and then analyzed using one-way ANOVA with Tukey's multiple comparisons and twoway ANOVA. Questions 12 and 13 were analyzed by chi squared tests. Alpha was set at 0.05 for all statistical analysis.

\section{Results and Discussion}

Forty-one fourth grade students (19 boys and 22 girls) and 33 fifth grade students (16 boys and 17 girls) participated in this study.
Seventeen students ( 9 boys and 8 girls) participated in the study in both fourth and fifth grade.

Overall, there were no differences in FitnessGram data between fourth grade boys and girls for the PACER, Flexed Arm Hang, Curl-up, Trunk Lift, or Shoulder Stretch assessments (Table 2). However, girls performed better on the left and right-side Sitand-Reach ( $p=0.022$ and $p=0.033$, respectively), which measures lumbar and hamstring muscle flexibility. Fifth grade FitnessGram data was similar; girls performed better on the left and right-side Sitand-Reach ( $p=0.016$ and $p=0.028$, respectively), but there were no differences in the other fitness assessments.

Table 3 shows data obtained from the proctored survey. All fourth and fifth graders ranked their risk of developing heart disease as well as the effects of heart disease similarly (questions 2 and 3). While fourth and fifth grade boys rated the effects of 
low PA similarly, fifth grade girls ranked the effects as less harmful than fourth grade girls (question $3 ; \mathrm{p}=$ 0.049).

Table 2 - Results of FitnessGram Assessments. Values are mean \pm SEM.

$*$ indicates significant difference from $4^{\text {th }}$ grade of same gender; $p<0.05$

$* *$ indicates significant difference from girls of same grade; $\mathrm{p}<0.05$

\begin{tabular}{|c|c|c|c|c|c|c|c|c|}
\hline \multirow{2}{*}{$\begin{array}{c}\text { FitnessGram } \\
\text { Assessments } \\
\text { Grade }\end{array}$} & \multicolumn{3}{|c|}{ Girls } & \multicolumn{3}{|c|}{ Boys } & \multicolumn{2}{|c|}{$\begin{array}{r}\text { Girls compared } \\
\text { to Boys }\end{array}$} \\
\hline & $4^{\text {th }}(n=22)$ & $5^{\text {th }}(n=17)$ & & $4^{\text {th }}(n=19)$ & $5^{\text {th }}(n=16)$ & & $4^{\text {th }}$ & $5^{\text {th }}$ \\
\hline & & & $p$ value & & & p value & $p$ value & p value \\
\hline $\begin{array}{c}\text { PACER } \\
(\mathrm{mL} / \mathrm{kg} / \mathrm{min})\end{array}$ & $55.1 \pm 0.8$ & $55.4 \pm 1.1$ & 0.996 & $54.2 \pm 1.1$ & $58.0 \pm 1.4$ & 0.080 & 0.934 & 0.374 \\
\hline $\begin{array}{l}\text { Flexed Arm Hang } \\
\text { (s) }\end{array}$ & $4.7 \pm 1.1$ & $5.7 \pm 1.1$ & 0.961 & $6.4 \pm 1.6$ & $7.7 \pm 2.0$ & 0.923 & 0.833 & 0.795 \\
\hline $\begin{array}{l}\text { Curl-ups } \\
\text { (\#) }\end{array}$ & $17.6 \pm 2.6$ & $17.0 \pm 2.3$ & 0.998 & $12.4 \pm 2.2$ & $15.6 \pm 2.1$ & 0.803 & 0.379 & 0.976 \\
\hline $\begin{array}{l}\text { Trunk Lift } \\
\text { (in) }\end{array}$ & $9.5 \pm 0.2$ & $10.2 \pm 0.3$ & 0.417 & $8.5 \pm 0.4$ & $9.0 \pm 0.5$ & 0.733 & 0.110 & 0.070 \\
\hline $\begin{array}{l}\text { Sit \& Reach } \\
\text { (L; in) }\end{array}$ & $11.2 \pm 0.4$ & $10.8 \pm 0.4$ & 0.904 & $9.4 \pm 0.5^{* *}$ & $8.8 \pm 0.4 * *$ & 0.744 & 0.022 & 0.016 \\
\hline $\begin{array}{l}\text { Sit \& Reach } \\
\quad(R ; \text { in) }\end{array}$ & $11.3 \pm 0.4$ & $10.5 \pm 0.5$ & 0.607 & $9.6 \pm 0.5^{* *}$ & $8.6 \pm 0.5 * *$ & 0.466 & 0.033 & 0.028 \\
\hline $\begin{array}{l}\text { Shoulder Stretch } \\
\text { (both sides } \\
\text { completed) }\end{array}$ & 18 of 22 & 15 of 17 & 0.679 & 15 of 19 & 13 of 16 & 0.865 & 0.817 & 0.576 \\
\hline
\end{tabular}

Table 3 - Results of proctored survey. Values are mean \pm SEM.

* indicates significant difference from $4^{\text {th }}$ grade of same gender; $p<0.05$

** indicates significant difference from girls of same grade; $p<0.05$

\begin{tabular}{|c|c|c|c|c|c|c|c|c|}
\hline Survey Questions & & Girls & & & Bo) & & Gir & $\begin{array}{l}\text { compared } \\
\text { to Boys }\end{array}$ \\
\hline \multirow[t]{2}{*}{ Grade } & $\begin{array}{c}4^{\text {th }} \\
(n=22)\end{array}$ & $\begin{array}{c}5^{\text {th }} \\
(n=17)\end{array}$ & & $\begin{array}{c}4^{\text {th }} \\
(n=19)\end{array}$ & $\begin{array}{c}5^{\text {th }} \\
(n=16)\end{array}$ & & $4^{\text {th }}$ & $5^{\text {th }}$ \\
\hline & & & $p$ value & & & p value & $p$ value & $p$ value \\
\hline $\begin{array}{l}\text { 1. How much do you feel at risk for } \\
\text { developing an unhealthy heart? }\end{array}$ & $2.5 \pm 0.6$ & $1.8 \pm 0.6$ & 0.808 & $1.5 \pm 0.5$ & $2.1 \pm 0.7$ & 0.930 & 0.642 & 0.984 \\
\hline $\begin{array}{l}\text { 2. How bad do you feel the effects } \\
\text { of an unhealthy heart are? }\end{array}$ & $7.7 \pm 0.7$ & $7.4 \pm 0.9$ & 0.990 & $7.1 \pm 0.7$ & $7.7 \pm 1.0$ & 0.971 & 0.956 & 0.995 \\
\hline $\begin{array}{l}\text { 3. How bad do you feel the effects } \\
\text { of low physical activity are? }\end{array}$ & $8.5 \pm 0.4$ & $6.1 \pm 1.0^{*}$ & 0.049 & $6.3 \pm 0.7$ & $8.0 \pm 0.6$ & 0.323 & 0.079 & 0.226 \\
\hline $\begin{array}{l}\text { 4. How would you rate the benefits } \\
\text { of physical activity on your overall } \\
\text { health? }\end{array}$ & $9.0 \pm 0.4$ & $9.2 \pm 0.2$ & 0.998 & $8.5 \pm 0.3$ & $7.1 \pm 0.8^{* *}$ & 0.163 & 0.870 & 0.026 \\
\hline $\begin{array}{l}\text { 5. How would you rate the benefits } \\
\text { of physical activity on making your } \\
\text { heart stronger? }\end{array}$ & $9.1 \pm 0.2$ & $9.2 \pm 0.2$ & 0.999 & $8.6 \pm 0.4$ & $8.8 \pm 0.3$ & 0.980 & 0.563 & 0.793 \\
\hline $\begin{array}{l}\text { 6. What prevents and/or } \\
\text { discourages you from physical } \\
\text { activity? Taken together, how } \\
\text { would you rate the level of their } \\
\text { overall } \\
\text { prevention/discouragement? }\end{array}$ & $3.6 \pm 0.7$ & $4.7 \pm 0.9$ & 0.729 & $3.3 \pm 0.8$ & $3.1 \pm 0.8$ & 0.995 & 0.995 & 0.493 \\
\hline $\begin{array}{l}\text { 7. What allows and/or encourages } \\
\text { you to be physically active? Rate } \\
\text { their overall level of } \\
\text { encouragement. }\end{array}$ & $8.2 \pm 0.3$ & $8.6 \pm 0.3$ & 0.971 & $7.6 \pm 0.7$ & $8.3 \pm 0.6$ & 0.743 & 0.731 & 0.985 \\
\hline $\begin{array}{l}\text { 8. What would allow and/or } \\
\text { encourage you to be more } \\
\text { physically active than you currently } \\
\text { are? How would you rate the } \\
\text { strength of encouragement from } \\
\text { these factors? }\end{array}$ & $7.1 \pm 0.7$ & $8.6 \pm 0.4$ & 0.403 & $7.7 \pm 0.7$ & $7.1 \pm 0.8$ & 0.898 & 0.905 & 0.430 \\
\hline $\begin{array}{l}\text { 9. How much do you think you can } \\
\text { increase your weekly physical } \\
\text { activity? }\end{array}$ & $7.6 \pm 0.5$ & $5.3 \pm 0.6$ & 0.095 & $5.4 \pm 0.9$ & $6.1 \pm 1.0$ & 0.931 & 0.146 & 0.857 \\
\hline $\begin{array}{l}\text { 10. How much do you think you can } \\
\text { improve your physical fitness? }\end{array}$ & $8.3 \pm 0.4$ & $4.7 \pm 0.8^{*}$ & 0.002 & $6.1 \pm 0.7$ & $5.8 \pm 0.9$ & 0.986 & 0.112 & 0.743 \\
\hline $\begin{array}{l}\text { 11. How much do you think you can } \\
\text { improve your overall health? }\end{array}$ & $7.9 \pm 0.5$ & $4.7 \pm 0.7^{*}$ & 0.004 & $6.7 \pm 0.7$ & $5.9 \pm 0.8$ & 0.800 & 0.579 & 0.635 \\
\hline
\end{tabular}


Additionally, there was a significant gender $x$ time interaction for question $3(p=0.004)$. Fifth grade boys rated the benefits of PA on their overall health significantly less than fifth grade girls (question $4 ; \mathrm{p}=$ 0.026 ). There were no differences in ratings between fourth grade boys and girls or between fourth and fifth grade boys or fourth and fifth grade girls. All groups scored the benefits of PA similarly (question 5).

Question 6 asked students to list the barriers that prevent/discourage PA. Fourth and fifth graders listed "technology" 19 times ( 6 boys and 13 girls) and 13 times ( 7 boys and 6 girls, respectively. Specific types of technology mentioned were: television, iPad, social media, Xbox and video games. "Homework" and "schoolwork" were mentioned 9 times by fourth graders ( 4 boys and 5 girls) and 8 times by fifth graders ( 1 boy and 7 girls) and the general term "busy" was listed one time by a fourth grade boy and 4 times by fifth graders ( 1 boy and 3 girls). Environmental barriers such as "rainy days", "winter", and "no friends in my neighborhood" were mentioned 8 times by fourth graders ( 4 boys and 4 girls) and 8 times by fifth graders ( 4 boys and 4 girls). Finally, "nothing" prevented 3 fourth grade boys and 5 fifth graders ( 4 boys and 1 girl) from being physically active. All fourth and fifth graders rated these PA barriers similarly in their level of overall prevention/discouragement.

Question 7 asked students to list factors that allow and/or encourage them to be physically active. Sports and recreational activities were mentioned 29 times by fourth graders (11 boys and 18 girls) and 17 times by fifth graders (7 boys and 10 girls). "Family", "friends", and "pets" were mentioned 17 times by fourth graders ( 6 boys and 11 girls) and 13 times by fifth graders ( 7 boys and 6 girls). Environmental factors were mentioned by 4 fourth grade boys and 5 fifth graders ( 1 boy and 6 girls). All fourth and fifth graders rated these factors similarly in their overall level of encouragement.

Question 8 asked students to list factors that would allow and/or encourage them to be more physically active than they currently were. Variations of "less school" and "no homework" were mentioned 14 times by fourth graders ( 4 boys and 10 girls) and 10 times by fifth graders ( 5 boys and 5 girls). Environmental factors, such as "more summertime" accounted for 14 responses from fourth graders (8 boys and 6 girls) and 11 responses from fifth graders ( 5 boys and 6 girls). Participating in more sports and recreational activities were listed 9 times by fourth graders ( 3 boys and 6 girls) and 9 times by fifth graders ( 6 boys and 3 girls). "Less technology" was listed 5 times by fourth graders ( 2 boys and 3 girls) and by one fifth grade girl. Parents, friends, siblings, and pets were mentioned 6 times by fourth graders (1 boy and 5 girls) and 9 times by fifth graders ( 3 boys and 6 girls). Finally, two fourth grade girls and one fifth grade boy wanted to get healthier, increase fitness, and lose weight. All fourth and fifth graders rated the strength of encouragement from these factors similarly.

There were no differences in fourth and fifth grade students' self confidence in increasing their weekly PA (question 9). However, fifth grade girls had less confidence that they could improve their physical fitness when compared to fourth grade girls (question $10 ; p=0.002)$. There was also a significant gender $x$ time interaction for questions $10(p=0.025)$. Finally, girls' confidence that they could improve their overall health significantly decreased from fourth to fifth grade (question 11, $\mathrm{p}=0.004$ ). There were no differences between fourth and fifth grade boys or girls and boys in each grade level.

Figures 1 and 2 show the answers to survey questions 12 and 13 , respectively. There were no significant differences between the number of fourth grade boys and girls $(p=0.207)$ or fifth grade boys and girls $(p=0.737)$ that were aware they needed 60 minutes of moderate-to-vigorous-intensity exercise per day. However, there was a significant difference in PA awareness in girls from fourth to fifth grade (9/22 compared to $13 / 17 ; p=0.026)$. There was no difference in PA awareness between fourth and fifth grade boys (11/18 compared to $13 / 16 ; p=0.198$ ). Question 13 asked students if they met the recommendation of 60 minutes of moderate-tovigorous-intensity exercise per day. Nineteen of 22 fourth grade girls, 12 of 18 fourth grade boys, 13 of 16 fifth grade girls, and 12 of 15 fifth grade boys answered yes. There were no significant differences between genders or grade levels for this question.

Main findings from this study are that girls' self-confidence in their abilities to improve fitness and overall health decreased from fourth to fifth grade (questions 10 and 11). This decrease is alarming because self-efficacy is a determinant of motivation and action and has been correlated with both current exercise behavior and exercise intent in middle school children [30, 31, 38]. 


\section{A: Fourth Grade}
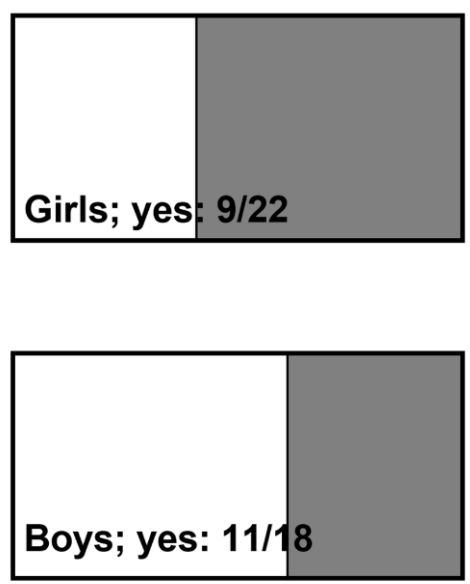

\section{B: Fifth Grade}

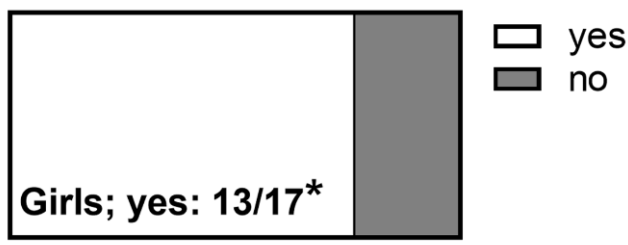

Boys; yes: $13 / 16$

Figure 1 - Response rate to Question 12: "Have you ever heard that $60 \mathrm{~min} /$ day of moderate or vigorous physical activity makes your heart stronger?" in fourth (A.) and fifth (B.) graders. Numbers in bars indicate student responses. * indicates significant difference from $4^{\text {th }}$ grade of same gender; $\mathrm{p}$ $<0.05$

\section{A: Fourth Grade}
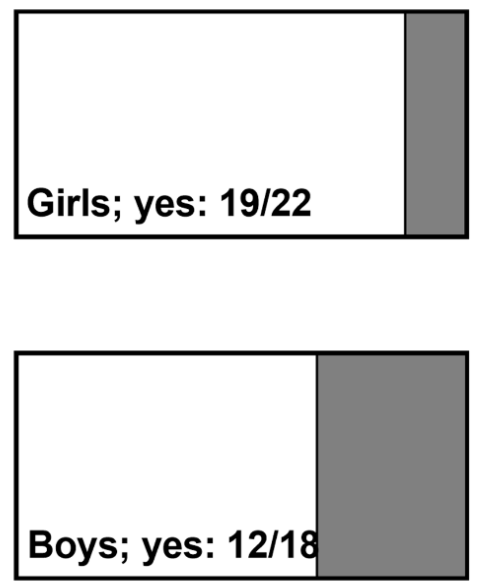

\section{B: Fifth Grade}

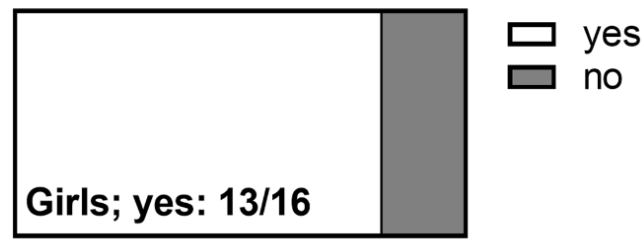

Boys; yes: 12/15

Figure 2 - Response rate to Question 13: "Do you currently do $60 \mathrm{~min} /$ day of moderate (breathing hard to where you can talk, but can't comfortably sing) or vigorous (can't comfortably speak a complete sentence without stopping to breathe) physical activity?" in fourth (A.) and fifth (B.) graders. Numbers in bars indicate student responses.

It is important to note that the FitnessGram results indicate the girls' confidence cannot be explained by differences in cardiorespiratory or muscular fitness. Fourth and fifth grade boys and girls performed similarly on all fitness assessments except for the flexibility test. In both fourth and fifth grade, girls performed significantly better than boys on the Sit-and-Reach assessment.Our results agree with previous studies that show girls' confidence and perceived competence decrease in elementary and middle schools $[12,39]$. One study found boys have a higher perceived competence in PE than girls did at both 8 and 12 years.
Moreover, there was a trend for girls' perceived competence to decrease from aged 8 years to 12 years, while boys' perceived competence remained the same over the same time period [16]. Importantly, perceived athletic competence has been associated with PE enjoyment in middle school children [40]. Further, lower perceived athletic competence was related to PE enjoyment and differed by gender [39]. A longitudinal study found that from fourth to sixth grade, boys had increased enjoyment in PE while girls reported a slight decrease in PE enjoyment [40]. Additionally, girls with lower perceived athletic competence reported decreasing PE enjoyment over 
the two-year study [40]. Taken together with our data, these studies suggest an association between selfefficacy, perceived competence in athletic abilities, and PE enjoyment regardless of fitness and athletic ability. Because self-efficacy is a determinant of being physically active, it follows that as girls' PE enjoyment and self-efficacy in athletic ability decline, so will their time spent in PA. To increase girls' self-confidence in their fitness abilities and time spent in PA, PE teachers should consider grade level and gender when designing curriculum $[41,42]$.

Another important finding was that fifth-grade girls rated the effects of low PA as less severe than they did the previous year in fourth grade (question 3 ). However, significantly more fifth grade girls than fourth grade girls were aware that 60 minutes of PA per day was beneficial for heart health (question 12). These beliefs about the negative effects of low PA spotlight shortfalls in PE and health curriculum. While it is commendable that more fifth grade girls know the recommended PA guidelines when compared to fourth grade girls, it is concerning that they believe the effects of not meeting these PA guidelines are less consequential on their health than they did the previous year. It is unclear if these beliefs are related to self-efficacy and time spent in PA. Finally, it is also important to note that despite their beliefs about the severity of low PA, fifth grade girls rated the benefits of PA on overall health higher than fifth grade boys (question 4).

The barriers to (question 6) and cues to action (questions 7 and 8) for PA listed by students in this study are similar to findings reported in the literature. For example, in children aged 8 to 10 years, parental support has been found to be a predictor for both participation and dropout in organized sport [17]. Multiple studies have found that children's activity levels correlate to both that of their parents and siblings [24-26]. However, it is important to note that throughout adolescence, peer influence on PA behavior increases while parental influence weakens [43, 44]. Perceived barriers to exercise reported by adolescents in the literature include environment, school work and responsibilities, and television watching $[45,46]$. While technology was seen as a barrier to PA by our students, it has also been used as an intervention strategy to increase PA $[47,48]$.

Technology can be an asset in the health and fitness landscape when it's utilized to combat the negative effects of inactivity by promoting PA. One technological measure that increases $P A$ is mobile health apps with wearable activity trackers [48, 49]. Wrist-worn devices and smartphones can monitor heart rate, steps taken, blood glucose, and more and they can be incorporated into daily life to aid in health behavior change [47-49]. Another application of technology that could increase PA is virtual reality (VR). As a rehabilitation tool, VR exercise programs have been effective at improving physical function in both adults and children [50-52]. Application of this technology could provide a more mobile, active experience for children who currently play sedentary games. Finally, to address the PA gender gap, several organizations have been designed specifically to promote the PA of women and girls. Examples of these programs include Girls on the Run (www.girlsontherun.org), GirlTrek (www.girltrek.org), and the Women's Walking Program [53]. These programs encourage girls and women to increase daily PA through in-person meetings, apps, phone calls, and podcast. Through these organizations, members support each other and create a community that engages in PA together, despite being geographically separated.

\section{Conclusion}

In conclusion, our data shows that from fourth to fifth grade, girls' confidence that they could improve their physical fitness and their overall health significantly decreased. This decreased self-confidence persists and is also seen in women in college. The cause of this decrease in self-confidence is most likely multifactorial and more research is needed to elucidate why these changes in self-confidence occur. Our study also illustrates that there are clear gender gaps in adolescents' beliefs about PA and more research is needed to determine how perceived self-confidence and competence in athletic abilities contribute to gender discrepancies in time spent in PA. To increase girls' self-confidence in their fitness abilities and time spent in PA, PE teachers should consider grade level and gender when designing curriculum. We propose PE programs throughout all grades dedicate more time to and find more ways to incorporate the importance of healthy behaviors, including time spent in PA, and work to build and maintain self-confidence in all students, especially girls. A focus on healthy behaviors, that begins in elementary school, could help decrease incidences of cardiovascular disease and other chronic illnesses in American adults. 
References

[1] F.A. Barwais, Assessing Physical Activity and .S. Virani, et al., Heart disease and stroke statistics - 2021 update: A report from the American Heart Association, Circulation, 143(8) (2021) e254-e743. [DOI] [PubMed]

[2] N.T. Artinian, et al., Interventions to promote physical activity and dietary lifestyle changes for cardiovascular risk factor reduction in adults: a scientific statement from the American Heart Association. Circulation, 122(4) (2010) 406-441. [DOI] [PubMed]

[3] B.A. Dennison, J.H. Straus, E.D. Mellits, and E. Charney, Childhood physical fitness tests: predictor of adult physical activity levels? Pediatrics, 82(3) (1988) 324-330. [PubMed]

[4] K.E. Powell and W. Dysinger, Childhood participation in organized school sports and physical education as precursors of adult physical activity, American Journal of Preventive Medicine, 3(5) (1987) 276-281. [PubMed]

[5] W.L. Haskell, I.M. Lee, R.R. Pate, K.E. Powell, S.N. Blair, B.A. Franklin, C.A. Macera, G. W. Heath, P.D. Thompson, and A. Bauman, Physical activity and public health: updated recommendation for adults from the American College of Sports Medicine and the American Heart Association, Circulation, 116(9) (2007) 1081-1093. [DOI] [PubMed]

[6] Office of Disease Prevention and Health Promotion, Healthy People 2020. U.S Department of Health and Human Services, Washington, D.C.

[7] U.S Department of Health and Human Services, (2018) Physical Activity Guidelines for Americans, $2^{\text {nd }}$ edition, U.S Department of Health and Human Services, Washington, D.C.

[8] C.L. Merlo, S.E. Jones, S.L. Michael, T.J. Chen, S.A. Sliwa, S.H. Lee, N.D. Brener, S.M. Lee, and S. Park, Dietary and physical activity behaviors among high school students - Youth Risk Behavior Survey, United States, 2019. MMWR Supplements, 69(1) (2020) 64-76. [DOI] [PubMed]

[9] Centers for Disease Control and Prevention, 2019 Youth Risk Behavior Survey Data. Available at: www.cdc.gov/yrbs

[10] S.G. Trost, R.R. Pate, J.F. Sallis, P.S. Freedson, W.C. Taylor, M. Dowda, and J. Sirard, Age and gender differences in objectively measured physical activity in youth, Medicine \& Science in Sports \& Exercise, 34(2) (2002) 350-355. [DOI] [PubMed]

[11] J.F. Sallis, Epidemiology of physical activity and fitness in children and adolescents, Critical Reviews in Food Science and Nutrition, 33(4-5) (1993) 403-408. [DOI] [PubMed]
[12] A. Luque-Casado, X. Mayo, A.M. Lavin-Perez, A. Jimenez, and F. del Villar, Understanding behavioral regulation towards physical activity participation: do we need a paradigm shift to close the gender gap? Sustainability, 13(4) (2021) 1683. [DOI]

[13] X. Mayo, A. Luque-Casado, A. Jimenez, and F. del Villar, Physical activity levels for girls and young adult women versus boys and young adult men in Spain: a gender gap analysis, Sustainability, 12(15) (2020) 6265. [DOI]

[14] J.R. Evans, R. Wilson, C. Coleman, W.Y.N. Man, and T. Olds, Physical activity among indigenous Australian children and youth in remote and non-remote areas, Social Science \& Medicine, 206 (2018) 93-99. [DOI] [PubMed]

[15] M.S. Pearce, L. Basterfield, K.D. Mann, K.N. Parkinson, A.J. Adamson, and J.J. Reilly, Early predictors of objectively measured physical activity and sedentary behaviour in 8-10 year old children: the Gateshead Millennium Study, PLoS One, 7(6) (2012) e37975. [DOI] [PubMed]

[16] R.M. Telford, R.D. Telford, L.S. Olive, T. Cochrane, and R. Davey, Why are girls less physically active than boys? Findings from the LOOK Longitudinal Study, PLoS One, 11(3) (2016) e0150041. [DOI] [PubMed]

[17] S.A. Vella, D.P. Cliff, and A.D. Okely, Socioecological predictors of participation and dropout in organised sports during childhood, International Journal of Behavioral Nutrition and Physical Activity, 11 (2014) 62. [DOI] [PubMed]

[18] J.A. Sarkin, T.L. McKenzie, and J.F. Sallis, Gender differences in physical activity during fifth-grade physical education and recess periods, Journal of Teaching in Physical Education, 17(1) (1997) 99-106. [DOI]

[19] T.L. McKenzie, S.J. Marshall, J.F. Sallis, and T.L. Conway, Leisure-time physical activity in school environments: an observational study using SOPLAY, Preventive Medicine, 30(1) (2000) 70-77. [DOI] [PubMed]

[20] T.L. McKenzie, S.J. Marshall, J.F. Sallis, and T.L. Conway, Student activity levels, lesson context, and teacher behavior during middle school physical education, Research Quarterly for Exercise and Sport, 71(3) (2000) 249-59. [DOI] [PubMed]

[21] J.F. Sallis, et al., Determinants of physical activity and interventions in youth, Medicine \& Science in Sports \& Exercise, 24(6 Suppl) (1992) S248-S257. [PubMed]

[22] C.L. Edwardson, T. Gorely, N. Pearson, and A. Atkin, Sources of activity-related social support and adolescents' objectively measured afterschool and weekend physical activity: gender and age differences, Journal of Physical 
Activity and Health, 10(8) (2013) 1153-1158. [DOI] [PubMed]

[23] M. Hohepa, R. Scragg, G. Schofield, G.S. Kolt, and D. Schaaf, Social support for youth physical activity: Importance of siblings, parents, friends and school support across a segmented school day, International Journal of Behavioral Nutrition and Physical Activity, 4 (2007) 54. [DOI] [PubMed]

[24] L.L. Moore, D.A. Lombardi, M.J. White, J.L. Campbell, S.A. Oliveria, and R.C. Ellison, Influence of parents' physical activity levels on activity levels of young children, Journal of Pediatrics, 118(2) (1991) 215-219. [DOI] [PubMed]

[25] J.F. Sallis, T.L. Patterson, M.J. Buono, C.J. Atkins, and P.R. Nader, Aggregation of physical activity habits in Mexican-American and Anglo families, Journal of Behavioral Medicine, 11(1) (1988) 31-41. [DOI] [PubMed]

[26] J.F. Sallis, T.L. Patterson, T.L. McKenzie, and P.R. Nader, Family variables and physical activity in preschool children, Journal of Developmental \& Behavioral Pediatrics, 9(2) (1988) 57-61. [PubMed]

[27] E. Shvartz and R.C. Reibold, Aerobic fitness norms for males and females aged 6 to 75 years: a review, Aviation, Space, and Environmental Medicine, 61(1) (1990) 3-11. [PubMed]

[28] J.R. Thomas and K.E. French, Gender differences across age in motor performance a meta-analysis, Psychological Bulletin, 98(2) (1985) 260-282. [PubMed]

[29] W.O. Eaton and L.R. Enns, Sex differences in human motor activity level, Psychological Bulletin, 100(1) (1986) 19-28. [PubMed]

[30] A. Bandura, (1986) Social Foundations of Thought and Action: A Social Cognitive Theory, Prentice-Hall, Englewood Cliffs, New Jersey.

[31] K.J. Ferguson, C.E. Yesalis, P.R. Pomrehn, and M.B. Kirkpatrick, Attitudes, knowledge, and beliefs as predictors of exercise intent and behavior in schoolchildren, Journal of School Health, 59(3) (1989) 112-115. [DOI] [PubMed]

[32] A.K. Leal, E. Fernandini, B. Jackson, M. Mason, and D. Elmer, A required college wellness course changes beliefs, attitudes, and behaviors related to physical activity, International Journal of Physical Education, Fitness and Sports, 8(1) (2019) 110-121. [DOI]

[33] M.D. Meredith and G. Welk, (2004) Fitnessgram/Activitygram: Test Administration Manual, Human Kinetics, Champaign, Illinois.

[34] I.M. Rosenstock, Historical Origins of the Health Belief Model, Health Education Monographs, 2(4) (1974) 328-335.

[35] I.M. Rosenstock, V.J. Strecher, and M.H. Becker, Social learning theory and the Health
Belief Model, Health Education Quarterly, 15(2) (1988) 175-183. [DOI] [PubMed]

[36] N.D. Weinstein, The precaution adoption process, Health Psychology, 7(4) (1988) 355386. [DOI] [PubMed]

[37] N.D. Weinstein, A.J. Rothman, and S.R. Sutton, Stage theories of health behavior: conceptual and methodological issues, Health Psychology, 17(3) (1998) 290-299. [DOI] [PubMed]

[38] S.H.Z. Sani, Z. Fathirezaie, S. Brand, U. Puhse, E. Holsboer-Trachsler, M. Gerber, and S. Talepasand, Physical activity and self-esteem: testing direct and indirect relationships associated with psychological and physical mechanisms, Neuropsychiatric Disease and Treatment. 12 (2016) 2617-2625. [DOI] [PubMed]

[39] Editorial, Time to tackle the physical activity gender gap, The Lancet Public Health, 4(8) (2019) E367-E368. [DOI] [PubMed]

[40] J. Cairney, M.Y. Kwan, S. Velduizen, J. Hay, S.R. Bray, and B.E. Faught, Gender, perceived competence and the enjoyment of physical education in children: a longitudinal examination, International Journal of Behavioral Nutrition and Physical Activity, 9 (2012) 26. [DOI]

[41] P.H. Kulinna, J.J. Martin, Q. Lai, A. Kliber, and B. Reed, Student physical activity patterns: Grade, gender, and activity influences, Journal of Teaching in Physical Education, 22(3) (2003) 298-310. [DOI]

[42] M. Parri and A. Ceciliani, Best practice in P.E. for gender equity- A review. Journal of Physical Education and Sport, 19(supplement 5) (2019) 1943-1952. [DOI]

[43] K.M. Greenockle, A.A. Lee, and R. Lomax, The relationship between selected student characteristics and activity patterns in a required high school physical education class, Research Quarterly for Exercise and Sport, 61(1) (1990) 59-69. [DOI] [PubMed]

[44] D. Buhrmester and W. Furman, The development of companionship and intimacy, Child Development, 58(4) (1987) 1101-1113. [DOI] [PubMed]

[45] S.G. Trost, R.R. Pate, M. Dowda, R. Saunders, D.S. Ward, and G. Felton, Gender differences in physical activity and determinants of physical activity in rural fifth grade children, Journal of School Health, 66(4) (1996) 145150. [DOI] [PubMed]

[46] M.K. Tappe, J.L. Duda, and P.M. Ehrnwald, Perceived barriers to exercise among adolescents, Journal of School Health, 59(4) (1989) 153-155. [DOI] [PubMed]

[47] A. Dzielska, J. Mazur, H. Nałęcz, A. Oblacińska, and A. Fijałkowska, Importance of self-efficacy in eating behavior and physical activity change 
of overweight and non-overweight adolescent girls participating in healthy me: a lifestyle intervention with mobile technology, Nutrients, 12(7) (2020) 2128. [DOI] [PubMed]

[48] S. Schoeppe, J. Salmon, S.L. Williams, D. Power, S. Alley, A.L. Rebar, M. Hayman, M.J. Duncan, and C. Vandelanotte, Effects of an Activity Tracker and App Intervention to Increase Physical Activity in Whole FamiliesThe Step It Up Family Feasibility Study, International Journal or Environmental Research and Public Health, 17(20) (2020) 7655. [DOI] [PubMed]

[49] A.M. Lee, S. Chavez, J. Bian, L.A. Thompson, M.J. Gurka, V.G. Williamson, and F. Modave, Efficacy and effectiveness of mobile health technologies for facilitating physical activity in adolescents: scoping review, JMIR Mhealth and Uhealth, 7(2) (2019) e11847. [DOI] [PubMed]

[50] C Cho, W. Hwang, S. Hwang, Y. Chung, Treadmill training with virtual reality improves gait, balance, and muscle strength in children with cerebral palsy, The Tohoku Journal of Experimental Medicine, 238(3) (2016) 213218. [DOI] [PubMed]

[51] E. Segura-Orti and A. Garcia-Testal, Intradialytic virtual reality exercise: increasing physical activity through technology, Seminars in Dialysis, 32(4) (2019) 331-335. [DOI] [PubMed]

[52] J.Y. Choi, S. Yi, L. Ao, X. Tang, X. Xu, D. Shim, B. Yoo, E.S. Park, and D. Rha, Virtual reality rehabilitation in children with brain injury: a randomized controlled trial, Developmental Medicine and Child Neurology, 63(4) (2021) 480-487. [DOI] [PubMed]

[53] D. Ingram, J. Wilbur, J. McDevitt, and S. Buchholz, Women's Walking Program for African American women: expectations and recommendations from participants as experts, Women \& Health, 51(6) (2011) 566-582. [DOI] [PubMed]

\section{Funding}

This research was funded by Bridgewater College.

\section{Authors Contribution}

Tenesha McDuffie: Investigation, Data Curation, Formal Analysis, Visualization, Writing - Original Draft Preparation. Mikaela Brooks: Investigation, Data Curation, Formal Analysis, Visualization, Writing Original Draft Preparation. Emily DeVilliers: Investigation, Data Curation, Formal Analysis, Visualization, Writing - Original Draft Preparation. Ashley Kelleran: Conceptualization, Methodology, Investigation, Supervision. Anna Leal:
Conceptualization, Methodology, Investigation, Formal Analysis, Funding Acquisition, Project Administration, Resources, Supervision, Validation, Visualization, Writing - Review \& Editing.

\section{Ethics Approval}

Approval was sought from the Bridgewater College Institutional Review Board.

\section{Informed Consent}

Guardian informed consent and personal informed assent was obtained from all subjects.

\section{Conflict of interest}

The Authors have no conflicts of interest to declare that they are relevant to the content of this article.

\section{Does this article screened for similarity? Yes}

\section{About The License}

(C) The Author(s) 2021. The text of this article is open access and licensed under a Creative Commons Attribution 4.0 International License 